Open Access

\title{
The A673T mutation in the amyloid precursor protein reduces the production of $\beta$-amyloid protein from its $\beta$-carboxyl terminal fragment in cells
}

\author{
Asuka Kokawa $^{1 \dagger}$, Seiko Ishihara ${ }^{1 \dagger}$, Hitomi Fujiwara', Mika Nobuhara ${ }^{1}$, Minori Iwata ${ }^{2}$, Yasuo Ihara ${ }^{2}$
} and Satoru Funamoto ${ }^{1 *}$

\begin{abstract}
Introduction: The A673T mutation in the amyloid precursor protein (APP) protects against Alzheimer's disease by reducing $\beta$-amyloid protein (A $\beta$ ) production. This mutation reduced the release of the soluble APP fragment (SAPP $\beta$ ), which is processed by $\beta$-secretase, suggesting a concomitant decrease in the $\beta$-carboxyl fragment of APP (C99), which is a direct substrate of $\gamma$-secretase for A $\beta$ production. However, it remains controversial whether the level of C99 is significantly reduced in cells expressing APP that carry A673T as the cause of reduced A $\beta$ production. Here, we investigated the effect of the A673T mutation in C99 on $\gamma$-cleavage in cells.
\end{abstract}

Results: We found that the level of C99 in cells expressing APP A673T was indistinctive of that observed in cells expressing wild-type APP, although the release of SAPP $\beta$ was significantly reduced in the APP A673T cells. In addition, our reconstituted $\beta$-secretase assay demonstrated no significant difference in $\beta$-cleavage on an APP fragment carrying the A673T mutation compared with the wild-type fragment. Importantly, cells expressing C99 containing the A673T mutation (C99 A2T; in accordance with the A $\beta$ numbering) produced roughly half the level of A $\beta$ compared with the wild-type C99, suggesting that the C99 A2T is an insufficient substrate of $\gamma$-secretase in cells. A cell-free $\gamma$-secretase assay revealed that A $\beta$ production from the microsomal fraction of cells expressing C99 A2T was diminished. A sucrose gradient centrifugation analysis indicated that the levels of the C99 A2T that was codistributed with $\gamma$-secretase components in the raft fractions were reduced significantly.

Conclusions: Our data indicate that the A673T mutation in APP alters the release of sAPP $\beta$, but not the C99 level, and that the C99 A2T is an inefficient substrate for $\gamma$-secretase in cell-based assay.

Keywords: Alzheimer's disease, Aß, APP, $\gamma$-secretase, C99, Lipid raft

\section{Introduction}

Senile plaques are one of neuropathological hallmarks of Alzheimer's disease $(\mathrm{AD})$ and composed of $\beta$-amyloid protein $(A \beta)$. $A \beta$ is a small protein consisting of $38-43$ residues that is produced from the amyloid precursor protein (APP) via sequential cleavage by $\beta$ - and $\gamma$-secretases $[1-5]$. Longer forms of $A \beta$, such as $A \beta 42$ and $A \beta 43$, are prone to aggregation and are initially deposited in the brain [6].

\footnotetext{
*Correspondence: sfunamot@mail.doshisha.ac.jp

${ }^{+}$Equal contributors

'Department of Neuropathology, Graduate School of Life and Medical

Sciences, Doshisha University, Kyotanabe, Kyoto 610-0394, Japan

Full list of author information is available at the end of the article
}

Familial AD (FAD) mutations in APP, presenilin 1, and presenilin 2 increase the ratio of $A \beta 42 / A \beta 40$. We found previously that FAD mutations preferentially produced a longer form of the APP intracellular domain (AICD49-99), rather than AICD50-99, and that the expression of $A \beta 48$, as a counterpart of AICD49-99, resulted in an increase in A $\beta 42 / A \beta 40$ ratio, as found for FAD mutations $[7,8]$.

Genetic analyses in AD provide not only insights into the molecular mechanisms underlying the pathogenesis of $\mathrm{AD}$, but also a perspective regarding the prevention and cure of the disease. Recently, the A673T mutation in APP was reported as a novel protective mutation 
against $\mathrm{AD}$ that acts by reducing $\mathrm{A} \beta$ production [9]. Although this mutation seems to be restricted to Iceland and Nordic countries, this finding, together with FAD mutations, strongly supports the amyloid hypothesis [10-17]. The A673T mutation causes a substantial decrease in the level of the soluble APP fragment processed by $\beta$-secretase $(\operatorname{sAPP} \beta)[9,18]$. It is reported that the level of the $\beta$-carboxyl fragment of APP (C99, also known as $\beta$ CTF and CTF $\beta$ ), which is a direct substrate of $\gamma$-secretase for $A \beta$ production, in cells expressing APP A673T was one fourth of that detected in cells expressing APP wild-type (WT), which suggests the concomitant decrease of $\mathrm{C} 99$ as a counterpart of sAPP $\beta$ [18]. Conversely, Benilova and colleagues reported that cells expressing APP A673T exhibited no significant difference in the levels of C99 compared with cells expressing WT APP, in spite of a nearly two hundredth reduction in sAPP $\beta$ levels [19]. Thus, it is unclear whether a decrease in $\mathrm{SAPP} \beta$ leads to a concomitant decrease in $C 99$ as a cause of reduced $A \beta$ production in cells expressing APP A673T.

Recently, we found that $\gamma$-secretase preferentially cleaved substrates with a short ectodomain, which supports the idea that $\gamma$-secretase recognizes the amino terminus of the substrate $[20,21]$. The A673T mutation (i.e., A2T; in accordance with the $A \beta$ numbering) lies within the amino terminus of the C99 substrate. It remains unknown whether the A2T substitution in C99 affects $\gamma$-secretasedependent cleavage in cells. In this study, we examined the direct effect of A2T substitution in C99 on $\gamma$-secretasedependent cleavage.

\section{Materials and methods Antibodies}

Cell lysates and conditioned media were subjected to western blotting using the following antibodies: $6 \mathrm{E} 10$ (total $\mathrm{A} \beta$; Covance), 82E1 (total $\mathrm{A} \beta$; IBL), E50 (total $\mathrm{A} \beta$ ), BA27 (Aß40), BC05 (Aß42), and anti-GFP (Santa Cruz) [22, 23].

\section{Constructs}

The C99-FLAG tag-coding region was fused to the APP signal peptide. Additional Asp and Ala residues were inserted between the APP signal peptide and C99-FLAG, which allowed precise cleavage at the $\beta$-cleavage site, generating $C 99$ and $A \beta$ species that start from Asp- $1[8,24]$. This C99-FLAG coding region or full-length APP region was inserted prior to the internal ribosome entry site (IRES) of pMXIG. This construct allows cells to express GFP as an internal standard. For pulse-chase analysis, the full-length APP-FLAG tag-coding region was inserted into pcDNA4/TO (Invitrogen) and transfected in T-Rex CHO cells (Invitrogen).

\section{Pulse-chase analysis of APP processing}

T-Rex CHO cells were cultured in 12-well plates and transfected with pcDNA4/TO carrying full-length APP (WT or A673T) [25]. Twenty-four hours later, cells were treated with tetracycline at a concentration of $1 \mu \mathrm{g} / \mathrm{mL}$ for $4 \mathrm{~h}$, to express APP. Cells were washed twice in tetracycline-free medium and incubated in the medium for $24 \mathrm{~h}$. Cells and media were collected every $4 \mathrm{~h}$ and subjected to western blotting, to visualize and quantify the levels of APP, sAPP $\beta$, sAPP $\alpha, C 99, C 83$, and A $\beta$.

\section{Secretase assays}

A $\gamma$-secretase assay and coimmunoprecipitation analyses were performed as described previously $[21,26]$. Briefly, the C99-FLAG substrate was expressed in sf9 cells and purified using anti-FLAG M2 agarose beads. The C99FLAG substrate was incubated with a $\gamma$-secretase fraction for $4 \mathrm{~h}$ and subjected to western blotting. For coimmunoprecipitation of C99 with $\gamma$-secretase components, the C99-FLAG substrate was immobilized on anti-FLAG M2 magnetic beads and incubated with a $\gamma$-secretase fraction. For $\beta$-secretase assay, the human APP fragment 633-685 (numbering from APP751) fused with N-terminal Myc and C-terminal FLAG tags (referred to as APP633-685-FLAG) was expressed in Escherichia coli BL21 cells and affinity purified using ANTI-FLAG M2 beads [21]. The purified APP633-685-FLAG (500 nM) was incubated with $\beta$ secretase (Sigma) for $4 \mathrm{~h}$, according to the manufacturer's instructions. $\beta$-Cleaved $\mathrm{C}$-terminal fragments (Aß33-FLAG) from APP633-685-FLAG were visualized and quantified using the E50 antibody.

\section{Cell-free $\gamma$-secretase assay}

Cells were cultured in Dulbecco's modified Eagle's medium (Sigma) supplemented with $10 \%$ FBS (Invitrogen) and penicillin/streptomycin (Invitrogen). Harvested cells were homogenized in Buffer A (20 mM PIPES, pH 7.0, $140 \mathrm{mM}$ $\mathrm{KCl}, 0.25 \mathrm{M}$ sucrose, and $5 \mathrm{mM}$ EGTA) with a glass/Teflon homogenizer. Postnuclear supernatants were subjected to ultracentrifugation at $100,000 \mathrm{~g}$ for $1 \mathrm{~h}$. The pellets were resuspended in Buffer A at a protein density of $2.5 \mathrm{mg} / \mathrm{mL}$ and defined as microsomal fractions [27]. Microsomal fractions from C99 WT and C99 A2T cells were incubated at $37^{\circ} \mathrm{C}$ and lipids were extracted with chloroform/methanol before western blotting.

\section{Isolation of CHAPSO-insoluble fractions}

The $\mathrm{CHO}$ homogenate was adjusted to $40 \%$ sucrose and centrifuged on a discontinuous sucrose gradient for $20 \mathrm{~h}$ at $4{ }^{\circ} \mathrm{C}$ using an SW $41 \mathrm{Ti}$ rotor (Beckman) $[28,29]$. After centrifugation, the homogenate was fractionated into 12 fractions and subjected to western blotting using the following antibodies: N1660 (Nicastrin; 1/3000 in TBS containing $0.1 \%$ Tween; Sigma), anti-Aph-1a C-term 
antibody (Aph-1; 1/1000 in TOYOBO Can Get Signal; Covance), anti-PS1-CTF antiserum (Presenilin 1 CTF; 1/ 3000 in TBS containing $0.1 \%$ Tween; gifts from Drs. T. Iwatsubo and T. Tomita, The University of Tokyo), anti-Pen-2 antibody (Pen-2; 1/3000 in TBS containing $0.1 \%$ Tween; a gift from Dr. A. Takashima, National Center for Geriatrics and Gerontology), anti-caveolin antibody (caveolin-1; 1/1000 in TBS containing $0.1 \%$ Tween; Santa Cruz), and anti-flotillin antibody (flotillin1; $1 / 1000$ in TBS containing $0.1 \%$ Tween; BD).

\section{Results}

\section{Effect of the A673T mutation on C99 levels in cells}

The A673T mutation in APP reduced the release of sAPP $\beta$ [9]. We also observed that the secretion of sAPP $\beta$ into the medium was diminished in $\mathrm{CHO}$ cells expressing APP A673T (APP A673T cells) (Fig. 1); however, the levels of C99 carrying A2T (C99 A2T) in APP A673T cells were not affected, which was in agreement with the study reported by Benilova and colleagues (Fig. 1b and c) [19]. To assess the rates of $\mathrm{sAPP} \beta, \mathrm{C} 99$, and $\mathrm{A} \beta$ generation from APP A673T, we performed a pulse-chase analysis of APP processing using the Tet-ON expression system (Fig. 2a). Although the generation rates of $\mathrm{SAPP} \beta$ and $\mathrm{A} \beta$ in APP A673T cells were attenuated, the generation rate of C99 in these cells was comparable to that observed in APP WT cells (Fig. 2b and c). Our observation was discrepant with a previous report [18]. To explain this disagreement, we focused on the immunoreactivity of $82 \mathrm{E} 1$, the antibody used in the ELISA system in the previous study. 82E1 was developed for amino-terminus-specific $A \beta$ detection [22]. Our western blot analyses indicated that 82E1 failed to detect C99 A2T and A $\beta$ A2T (Additional file 1: Figure S1). To confirm further the immunoreactivity of 82E1 on C99 A2 $\mathrm{T}$ in A673T cells, we performed immunoprecipitation of C99 A2T using 6E10 and 82E1. 6E10 captured C99, regardless of the substitution, whereas 82E1 failed to bind to C99 A2T (Additional file 1: Figure S2A). We also immunoprecipitated C99 A2T in the APP A673T cells with anti-FLAG M2 antibody recognizing carboxyl terminal of APP-FLAG and detected C99 A2T in APP A673T cells as well as C99 WT in APP WT cells with anti-FLAG M2, but not 82E1 (Additional file 1: Figure S2B). Our data demonstrated that the level of C99 in APP A673T cells was comparable to that detected in APP WT cells, despite a significant reduction in $\mathrm{SAPP} \beta$, suggesting that the level of C99 in APP A673T cells is insufficient to explain the reduced level of $A \beta$ secreted by these cells.

\section{Effect of the A673T mutation on the $\beta$-cleavage of the APP fragment}

The reduction in SAPP $\beta$ level observed in APP A673T cells suggests a reduced $\beta$-cleavage in APP A673T. However, we detected no significant reduction in C99 levels in APP A673T cells. This raises the possibility that the A673T mutation has no significant impact on the $\beta$ cleavage of APP. Although pioneer studies have demonstrated reduced $\beta$-cleavage of APP A673T, we revisited this issue $[9,18]$. We previously established a reconstituted $\beta$-secretase assay using the APP 633-685 substrate [21]. In this study, we examined the effect of the A673T mutation on the $\beta$-cleavage of the substrate carrying the mutation in our assay system. As shown in Fig. 3, APP 633-685-FLAG carrying A673T exhibited a level of A $333-$ FLAG production that was equivalent to that of the WT in our assay. This indicates that the A673T mutation does not affect the $\beta$-cleavage of APP.

\section{Effect of the A2T substitution on C99 regarding $A \beta$ production in cells}

To uncover the molecular mechanism underlying the involvement of the A673T mutation in reduced $\mathrm{A} \beta$ production, we tested whether the A2T substitution in C99 directly suppressed $A \beta$ production in cells (Fig. 1a). Importantly, CHO cells expressing C99 A2T (C99 A2T cells) released approximately half the levels of $A \beta 40$ and A 342 into the medium in the case of the WT C99 (C99 WT cells), whereas p3 40 levels in the C99 A2T medium were not affected at all (Fig. 4a). The alteration of $A \beta$ secretion by the expression of C99 A2T was observed even in other cell lines (Additional file 1: Figure S3). In addition, we found a significant reduction in intracellular $A \beta$ in C99 A2T cells (Fig. $4 b$ and c). These data demonstrate that the A2T substitution in C99 suppresses A $\beta$ production in cells.

\section{No effect of the A2T substitution in C99 on its $\gamma$-cleavage in a membrane-soluble state}

The A2T substitution lies within the amino terminus of C99, which is recognized by $\gamma$-secretase [20, 21]. One may expect that $\gamma$-secretase would fail to recognize C99 A2T because of suppressed $A \beta$ production. To test this possibility, we performed a CHAPSO-solubilized $\gamma$-secretase assay using the C99 A2T substrate, which allows free collision between the enzyme and substrate in the solution. Despite intensive analyses, we detected no significant reduction in $\mathrm{A} \beta$ production from recombinant $\mathrm{C} 99 \mathrm{~A} 2 \mathrm{~T}$ in the solution (Fig. 5a). Moreover, a coimmunoprecipitation analysis revealed that the interaction between $\mathrm{C} 99 \mathrm{~A} 2 \mathrm{~T}$ and $\gamma$ secretase components was not affected in the presence or absence of DAPT (Fig. 5b and c) [21].

\section{Effect of the A2T substitution on $A \beta$ production in microsomal fractions}

Data regarding $\mathrm{A} \beta$ production in the CHAPSO-solubilized $\gamma$-secretase assay contradicted the results of the cell-based assay in terms of C99 cleavage by $\gamma$-secretase. One possible explanation for this discrepancy is the altered distribution 


\section{a}

\begin{tabular}{|c|c|c|c|}
\hline \multicolumn{4}{|c|}{$\beta$-cleavage } \\
\hline APP WT & DAEFR... & IRES & GFP \\
\hline APP A673T & IDTEFR... & IRES & GFP \\
\hline C99 WT & \begin{tabular}{|l} 
DAEFR... \\
\end{tabular} & IRES & GFP \\
\hline C99 А2Т & DTEFR... & IRES & GFP \\
\hline
\end{tabular}

b
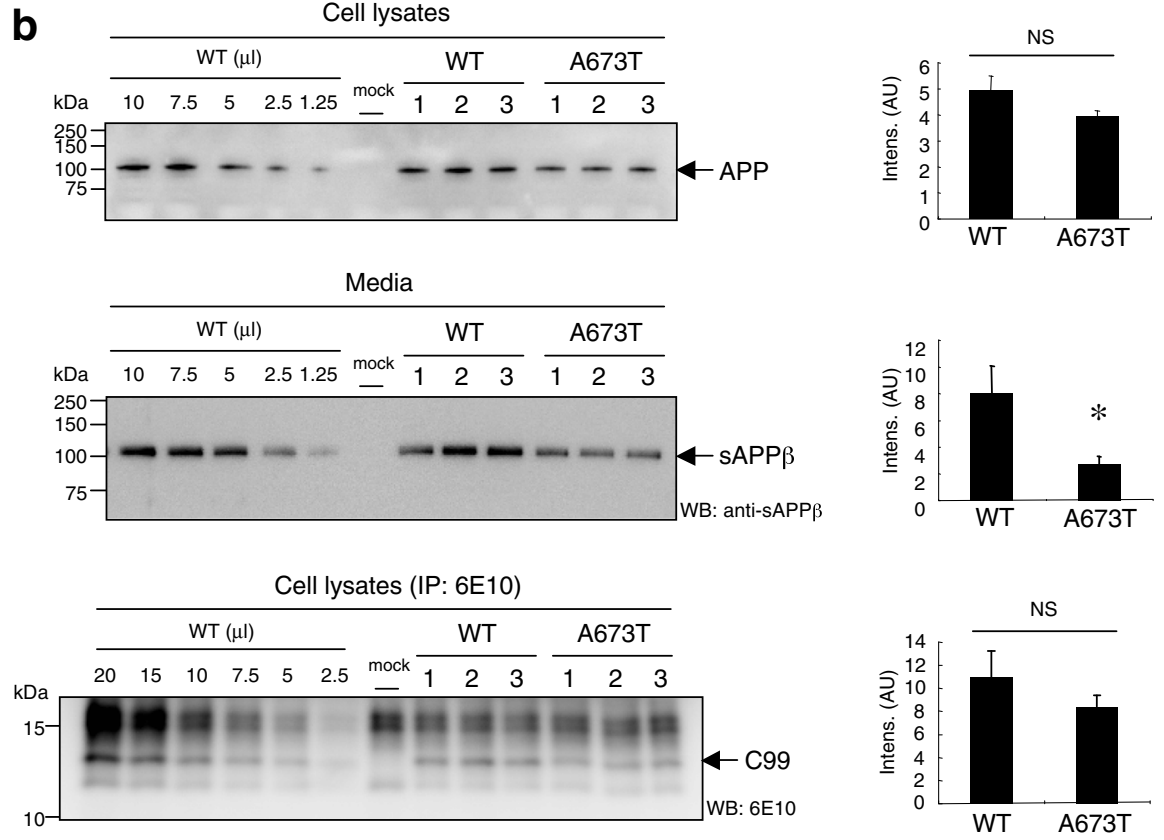

c
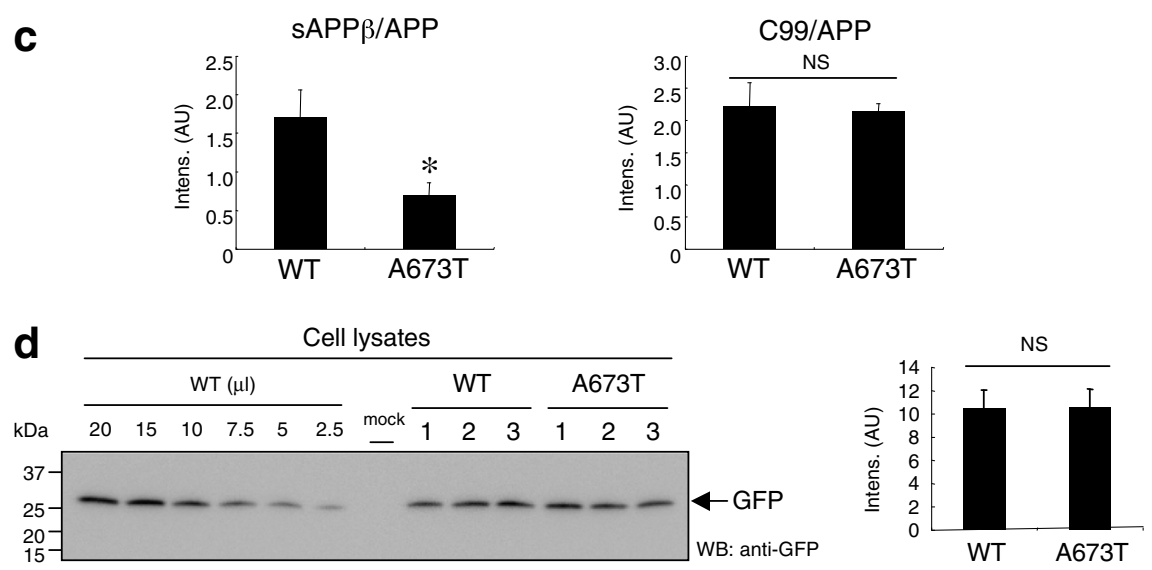

Fig. 1 The A673T substitution in APP decreased SAPP $\beta$ secretion, but not C99. Constructs used in this study. The APP695- or C99-coding fragment was inserted prior to IRES-GFP in PMXIG (a). APP A673T cells released one third of the levels of sAPP $\beta$ compared with those of wild-type APP. However, C99 levels in APP A673T cells were statistically indistinguishable from those of APP WT cells (b). Levels of SAPP 3 and C99 were normalized for amount of APP (c). C99 level in APP A673T cells was almost identical to that in wild-type APP cells, as well as from internal standard GFP expression levels (d). Data represent means \pm SD of three independent experiments. NS, not significant; ${ }^{*} P<0.05$ (unpaired $t$-test)

of C99 A2T at the membrane. C99 A2T may be recognized by $\gamma$-secretase inefficiently in certain membrane compartments, resulting in the inhibitory effect of the A2T substitution on $A \beta$ production in cells. To test this possibility, we performed a cell-free assay using the microsomal fraction of C99 A2T cells. We observed that C99 A2T yielded a significant decrease in $A \beta$ production in the cell-free assay, although the levels of C99 A2T and C99 WT were almost the same (Fig. 6). These findings imply that the A2T substitution alters the subcellular distribution of C99, which leads to interference with the interaction between $\gamma$ secretase and C99 in certain membrane compartments. 
Kokawa et al. Act Neuropathologica Communications (2015) 3:66

Page 5 of 12

a

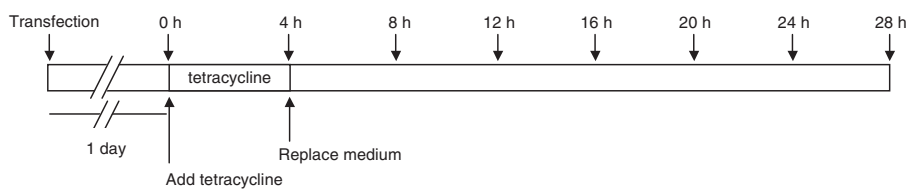

b

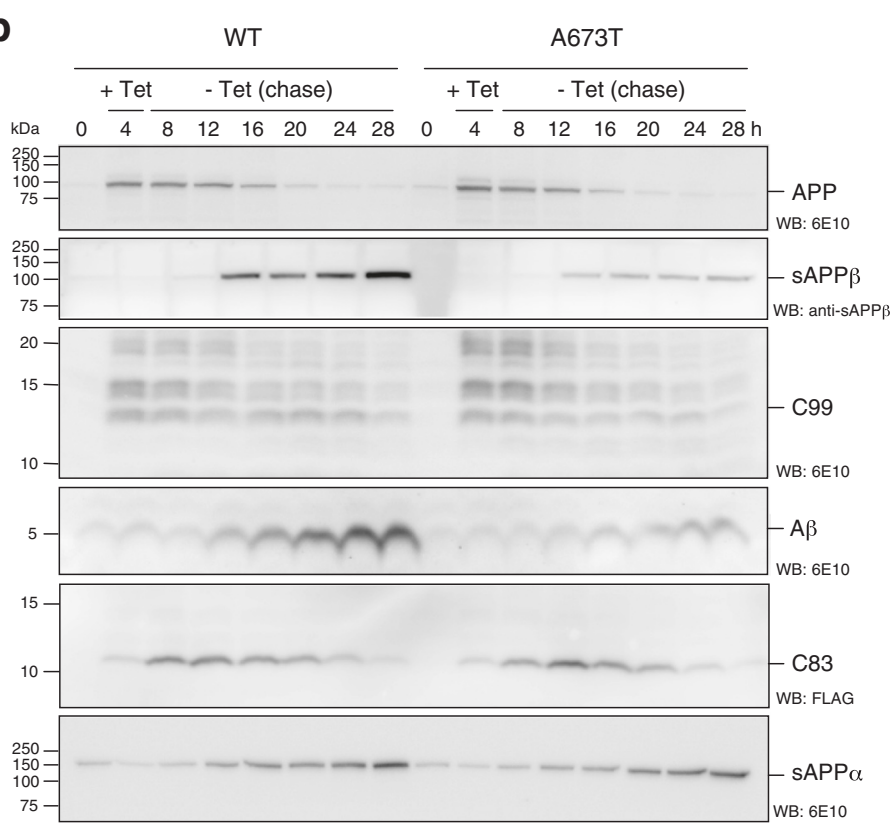

C
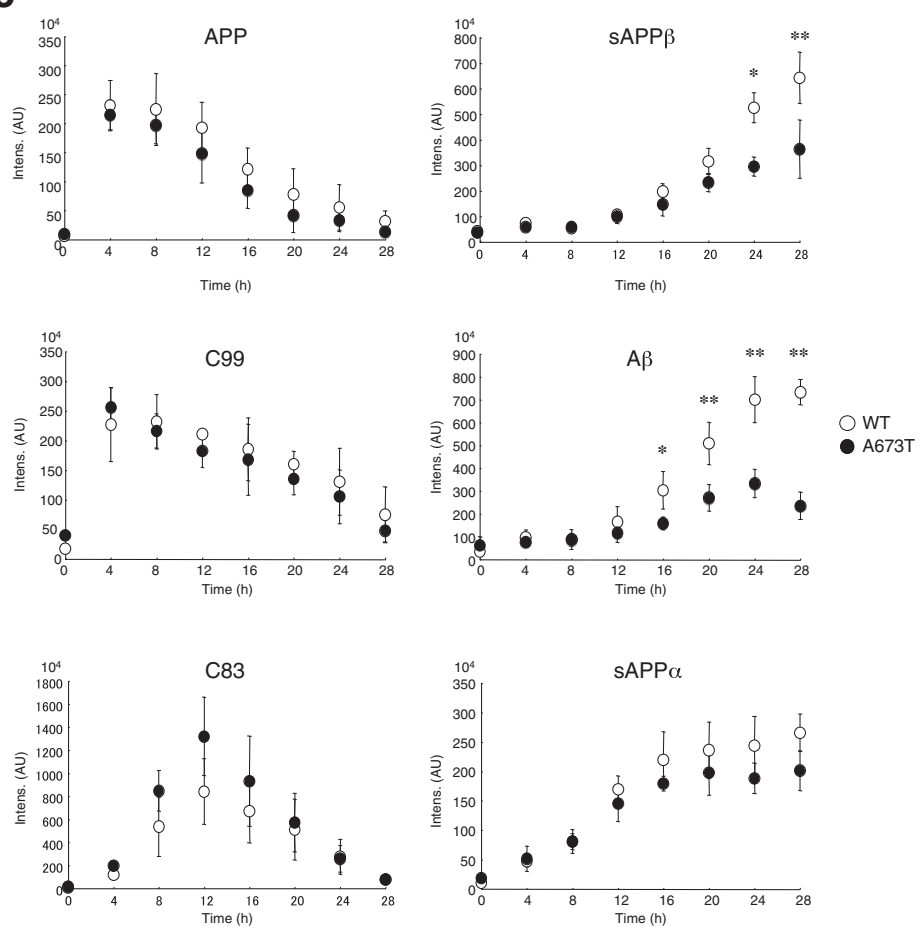

Fig. 2 (See legend on next page.) 
(See figure on previous page.)

Fig. 2 Pulse chase analysis of APP processing. Schematic diagram of pulse chase analysis of APP processing (a). CHO cells were transfected with APP WT or APP A673T construct and treated with $1 \mu \mathrm{g} / \mathrm{ml}$ tetracycline for $4 \mathrm{~h}$. After replacing media, cells and media were collected at the time indicated. Detection of APP, sAPPß, C99, A, C83 and SAPPa by Western Blotting (b). C99 was barely detected by using anti-FLAG antibody, although robust C83 bands were visualized. Quantitative analyses of APP, sAPP $\beta, C 99, A \beta, C 83$ and sAPPa (c). Levels of sAPP $\beta$ and $A \beta$ were reduced in APP A673T cells compared with those in APP WT cells, while levels of APP and C99 were almost similar to those of APP WT cells. It is interesting to note that generation rate of C83 is distinct from those of APP and C99. Data represent means \pm SD of three independent experiments. Open circle, WT; closed circle, A673T. ${ }^{*} P<0.05 ;{ }^{*} P<0.01$ (unpaired $t$-test)

\section{Altered distribution of C99 A2T in lipid rafts}

Active $\gamma$-secretase accumulates in detergent-insoluble fractions (lipid raft) of membranes prepared by sucrose gradient centrifugation [30-32]. C99 also distributes to these fractions, in part. To investigate whether C99 A2T exhibits an altered distribution in lipid rafts, C99 A2T cells were treated with $1 \%$ CHAPSO and subjected to sucrose gradient centrifugation as described previously $[28,29]$. Importantly, the levels of the C99 A2T that was codistributed with $\gamma$-secretase components in the raft fractions were reduced significantly, although we observed no prominent difference between C99 WT and C99 A2T in membrane, cytosolic and nuclear fractions (Fig. 7; Additional file 1: Figure S4-S5). Our data suggest that the altered subcellular distribution of C99 can result in a moderate interaction between $C 99$ and $\gamma$-secretase in cells, and in a reduction in $\mathrm{A} \beta$ production.

\section{Discussion}

The A673T mutation in APP has been recognized as a protective variant of late-onset of $\mathrm{AD}$ and has been related to longevity in an Icelandic population [9]. Although this variant is extremely rare in non-Nordic countries, it is important to explore the mechanism of reduced $A \beta$ production [14]. Biochemical and cell-based assays demonstrated reductions in the $\beta$-cleavage on an APP A673T fragment and in sAPP $\beta$ release from APP A673T cells, which suggests that reduced $\mathrm{C} 99$ production results in a reduction of $\mathrm{A} \beta$ production $[9,18]$. In fact, $\beta$-cleavage has been a promising drug target for anti-AD therapeutics, to reduce C99 and $A \beta[2,33]$. However, Benilova and colleagues observed no significant difference in the levels of C99 between APP WT and A673T cells, despite a substantial reduction in sAPP $\beta$ level [19]. This discrepancy prompted us to revisit this issue. In the present study, we showed that the level of
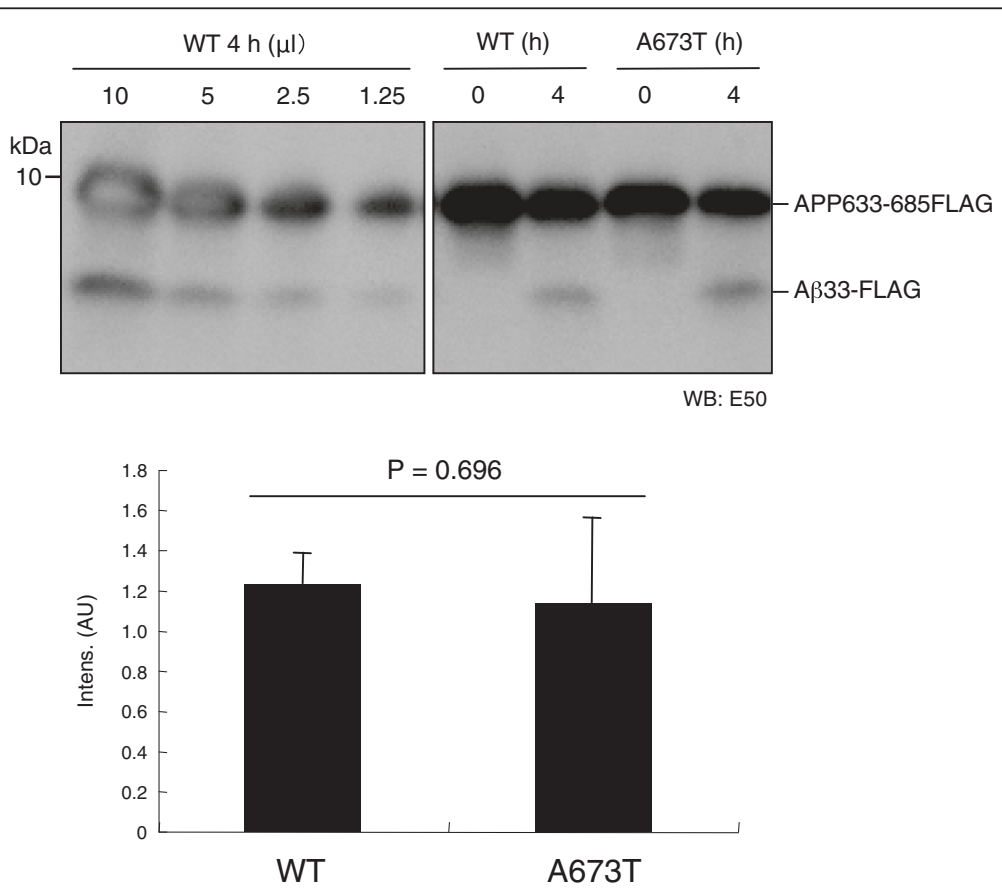

Fig. $3 \beta$-Secretase-dependent cleavage of the APP A673T fragment. An APP751 fragment (633-685) fused with FLAG tag (APP633-686-FLAG) was incubated with $\beta$-secretase. The E50 antibody was used to visualize the equal amounts of A 333 -FLAG that were produced by $\beta$-secretase from the WT of the APP633-686-FLAG substrate and its A673T mutant substrate. The reaction solution of the WT substrate was loaded onto a gel, as indicated by standard curve. Data are expressed as means \pm SD of three independent experiments. An unpaired $t$-test detected no significant differences between substrates 
a

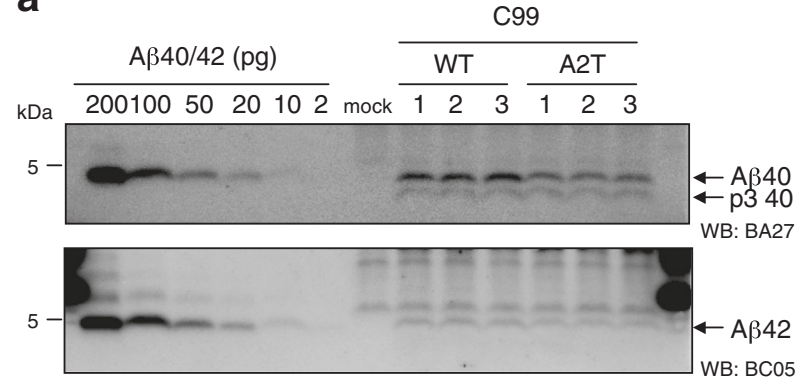

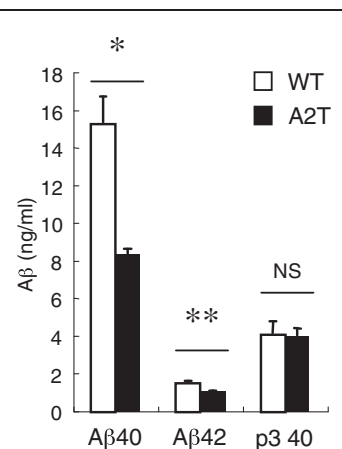

b

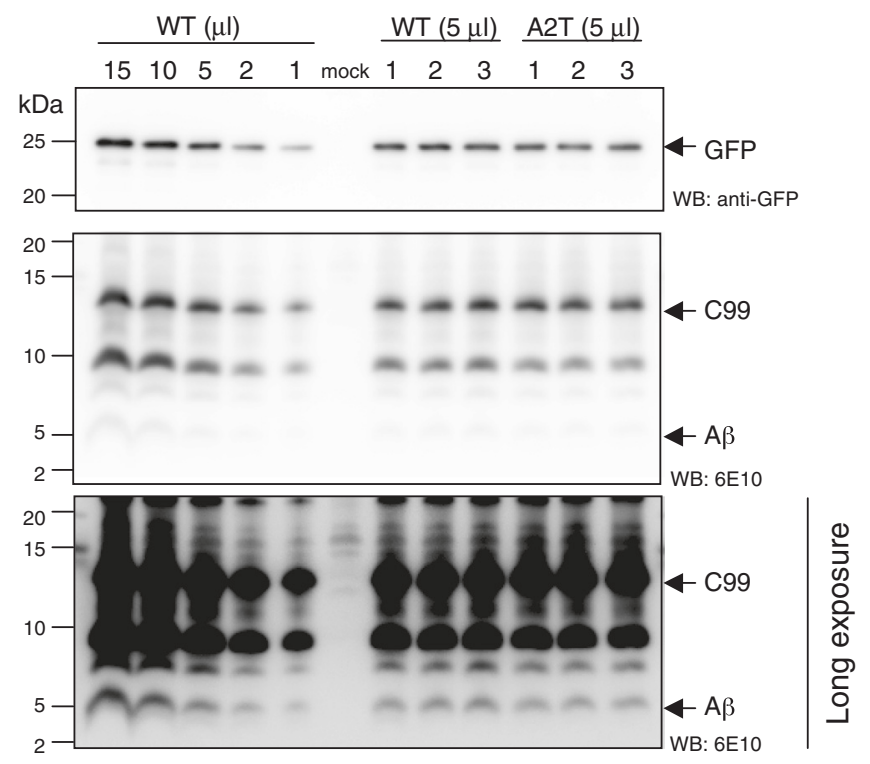

C
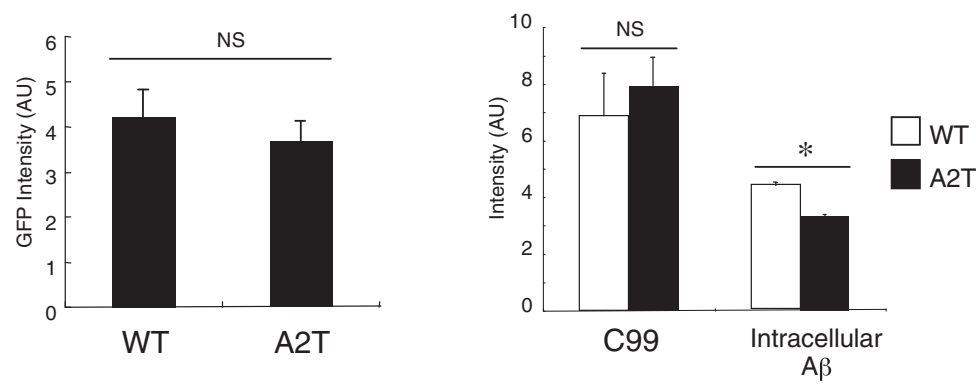

Fig. 4 Conditioned media of C99 WT and C99 A2T cells were subjected to Western blotting to visualize and quantify the AB and p3 species. C99 A2T cells exhibited reduced levels of $A \beta 40$ and $A \beta 42$, but not of p3 40 (a). Lysates of transfectants were subjected to Western blotting, to visualize and quantify GFP, C99, and intracellular A $(\mathbf{b})$. The lysate of C99 WT cells was loaded into a gel, as indicated by standard curve. The levels of GFP and C99 in cells expressing C99 WT and C99 A2T were indistinctive, whereas intracellular A levels were significantly reduced in C99 A2T cells. Data represent means \pm SD of three independent experiments (c). NS, not significant. ${ }^{*} P<0.05$ (unpaired $t$-test)

C99 in APP A673T cells was comparable to that detected in APP WT cells, despite a significant reduction in SAPP $\beta$. Currently, we do not have clear interpretations of the discrepancy between the amount of sAPP $\beta$ and C99 levels in APP A673T cells. However, it is interesting to note that the generation rate of $\mathrm{C} 83$ was distinct from that of $\mathrm{C} 99$, although the generation curves of sAPP $\alpha$ and $\operatorname{sAP} \beta$ had some resemblance to each other (see Fig. $2 \mathrm{~b}$ and $\mathrm{c}$ ). This suggests that the levels of those soluble APP fragments do not reflect the levels of their stubs in cells precisely.

Our reconstituted $\beta$-secretase assay demonstrated that the APP633-685 fragment carrying A673T was cleaved by $\beta$-secretase, as was the WT APP638-685 fragment. This result was consistent with our quantitative analyses 

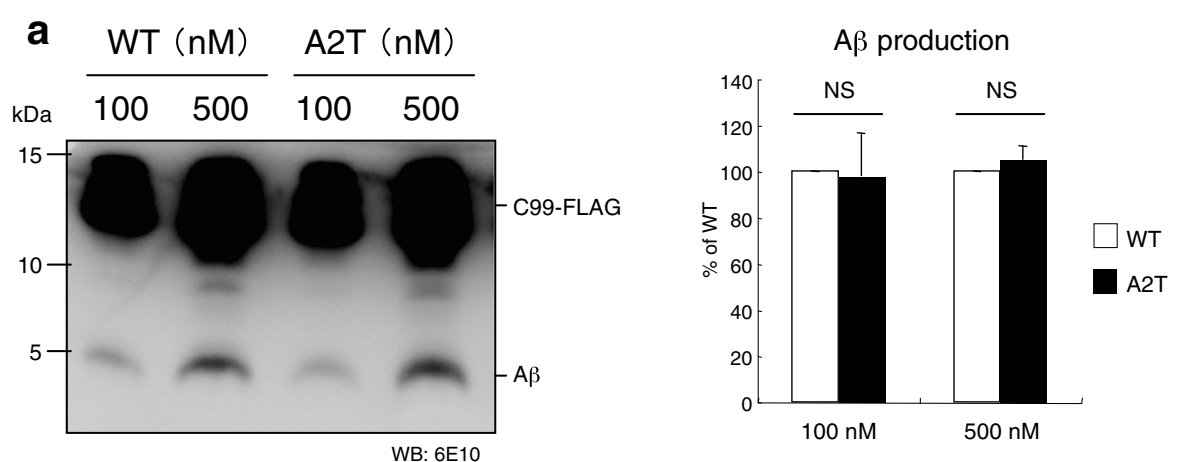

b

IP: M2 FLAG
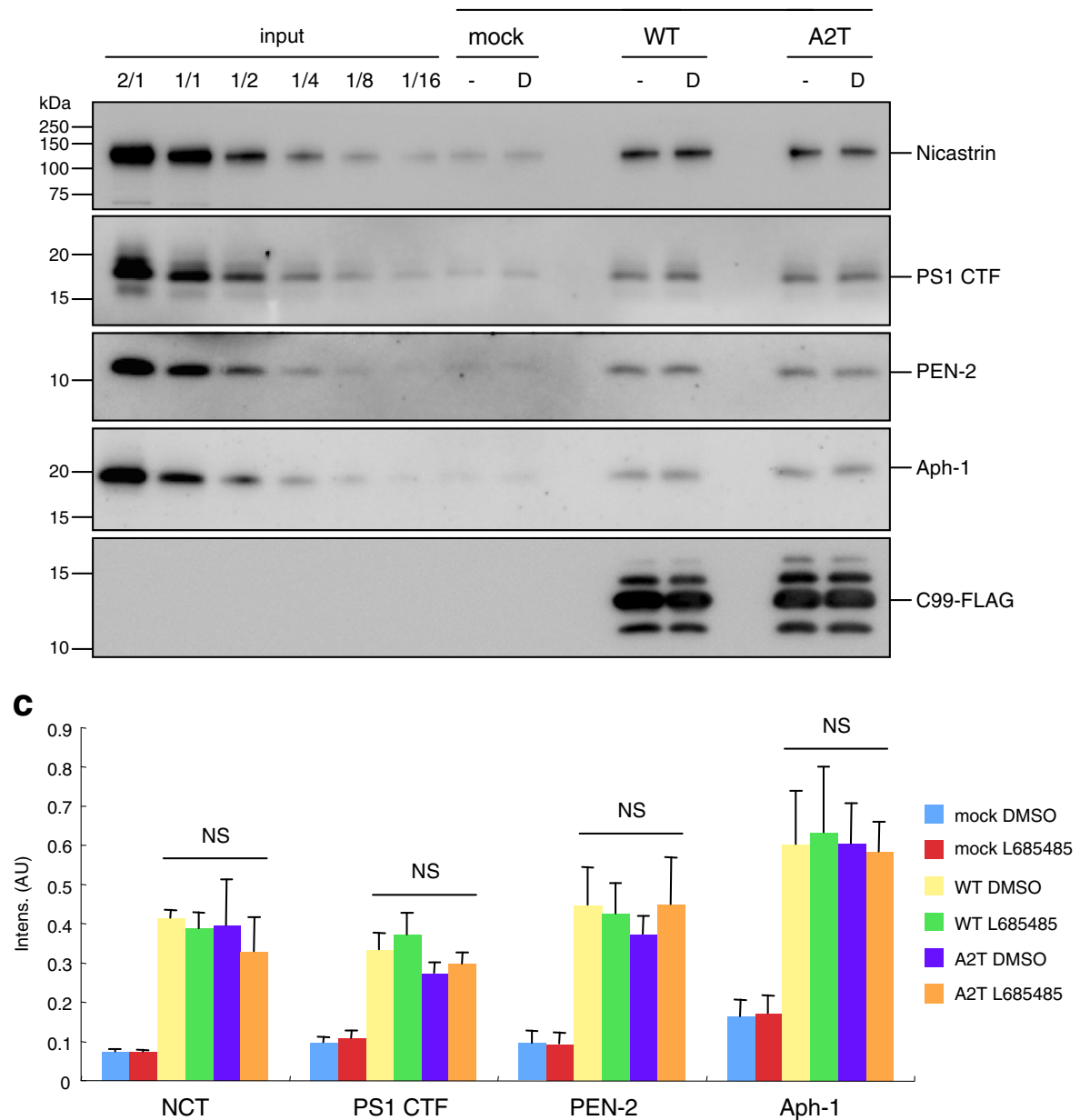

Fig. 5 CHAPSO-solubilized $\gamma$-secretase assay. Recombinant C99-FLAG substrates were incubated with solubilized $\gamma$-secretase and subjected to Western Blotting to visualize and quantify levels of A $\beta$ production (a). A production from C99 A2T was indistinctive to that from C99 WT. Data represent means \pm SD of three independent experiments. NS, not significant (unpaired t-test). Substrates were immobilized on anti-FLAG magnetic beads and incubated with CHAPSO-solubilized $\gamma$-secretase (b). After sufficient wash, the beads were subjected to Western Blotting. $y$-Secretase interacted with C99 A2T as well as C99 WT. -, DMSO vehicle control; D, 1 MM DAPT. Quantitative analyses of interacted $\gamma$-secretase components (c). Data represent means \pm SD of three independent experiments in the absence of 1 MM DAPT. NS, not significant (ANOVA, Scheffe's post hoc test compared with WT DMSO)

of C99 levels on A673T cells; however, it was inconsistent with the result of the cell-based assay of sAPP $\beta$ as reported previously $[9,18]$. One possible interpretation for the inconsistent results between the reconstituted $\beta$ - secretase assay and the cell-based assay is that APP A673T is preferentially processed by an unknown enzyme, leading to a reduced level of sAPP $\beta$ from APP A673T cells. Recently, Willem and colleagues reported 

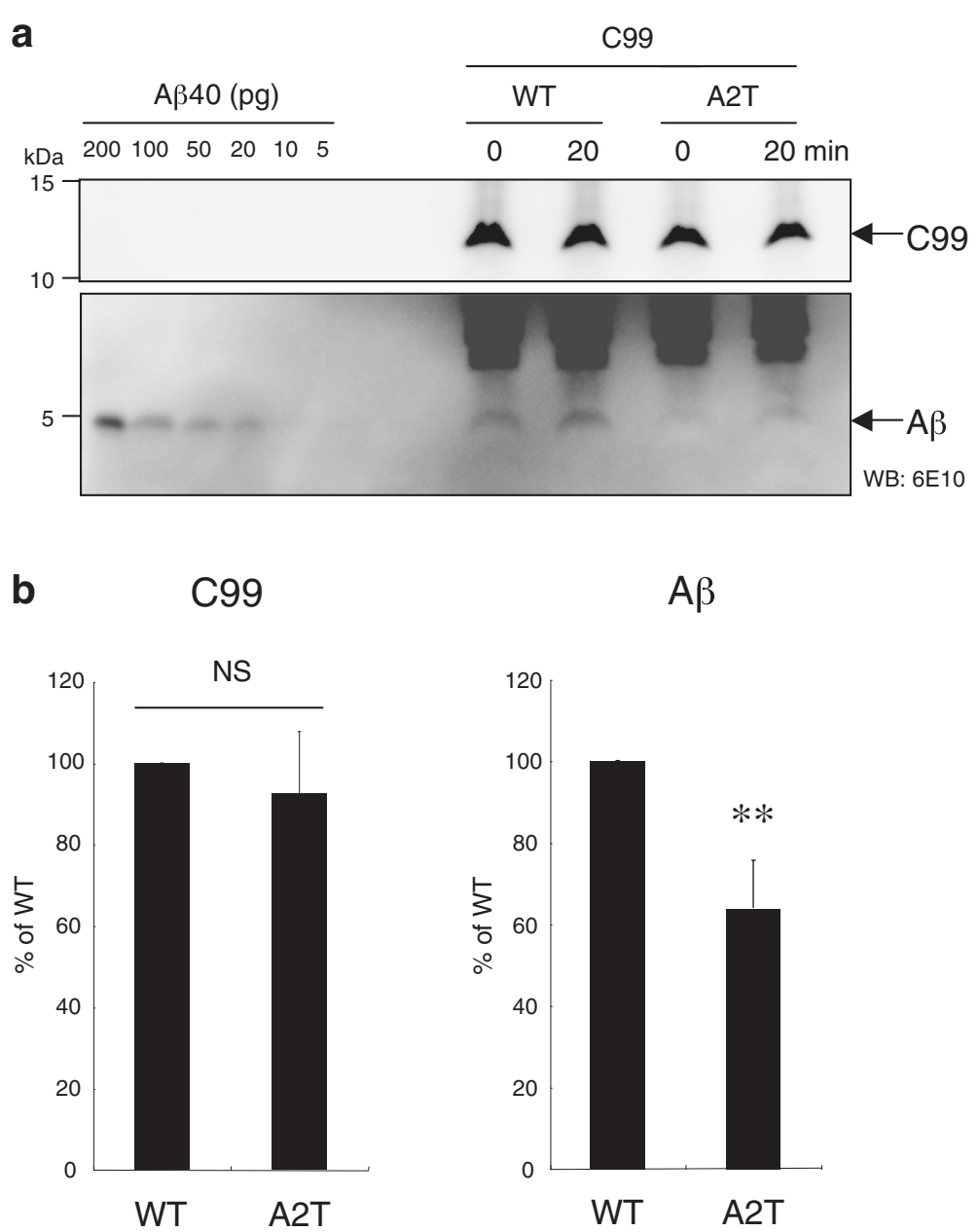

Fig. 6 The microsomal fraction of C99 A2T was incubated and subjected to Western Blotting analysis (a). A production from the microsomal fraction of C99 A2T cells was significantly reduced compared with that detected in C99 WT cells. A production was determined by subtracting the amount of $A \beta$ at 0 min from that at $20 \mathrm{~min}$. Data represent means \pm SD of four independent experiments (b). NS, not significant. ${ }^{* * P}<0.005$ (unpaired t-test)

$\eta$-secretase as a novel APP-processing enzyme that produces a high-molecular-weight carboxyl terminal fragment of APP (CTFn), which can be processed into C83 and C99 by $\alpha$ - and $\beta$-secretases, respectively [34]. One can safely say that $\eta$-secretase cleaves APP A673T preferentially. If so, APP A673T cells produce a lesser amount of sAPP $\beta$, but an equal level of C99, compared with APP WT cells. Alternatively, $\eta$-secretase may preferentially cleave sAPP $\beta$ produced from APP A673T cells.

We have shown that C99 A2T cells also release a lower amount of $\mathrm{A} \beta$ compared with C99 WT cells. This is direct evidence that the $\mathrm{A} 2 \mathrm{~T}$ substitution on $\mathrm{C} 99$ alters $\mathrm{A} \beta$ production. This was also observed for the other cell lines. Our western blotting assay using $6 \mathrm{E} 10$ and E50 revealed that $\mathrm{A} \beta \mathrm{A} 2 \mathrm{~T}$ and $\mathrm{C} 99 \mathrm{~A} 2 \mathrm{~T}$ were transferred onto nitrocellulose, as were A $\beta$ WT and C99 WT. Our data demonstrated that $82 \mathrm{E} 1$ failed to recognize $\mathrm{A} \beta \mathrm{A} 2 \mathrm{~T}$ and $\mathrm{C} 99 \mathrm{~A} 2 \mathrm{~T}$ on western blot and to capture the C99 A2T substrate on immunoprecipitation. This indicates that our evaluation by western blotting is reliable and that C99 A2T is an inefficient substrate for $A \beta$ production in cells. Importantly, the amount of the p3 peptide in the media of C99 WT and C99 A2T cells was indistinctive, which suggests that the A2T substitution affects the $\gamma$-cleavage of C99, but not that of C83. We also found that the A2T substitution in C99 caused no accumulation of intracellular $A \beta$; rather, it reduced the level of intracellular $A \beta$. Our data demonstrated that reduced $A \beta$ levels in the medium of $\mathrm{C} 99$ A2T cells were caused by impaired $\gamma$-cleavage of C99 A2T in cells.

We expected that C99 A2T would be an inefficient substrate for $\gamma$-secretase even in the CHAPSO-solubilized $\gamma$-secretase assay. However, we observed no significant reduction in $A \beta$ production from the recombinant $C 99 \mathrm{~A} 2 \mathrm{~T}$ substrate, and an interaction with $\gamma$-secretase components in the CHAPSO-solubilized state. This implies that membrane solubilization disrupts the intact distribution of C99 $\mathrm{A} 2 \mathrm{~T}$, which allows free collision between the enzyme and the substrate in the solution. To mimic the cell-based 


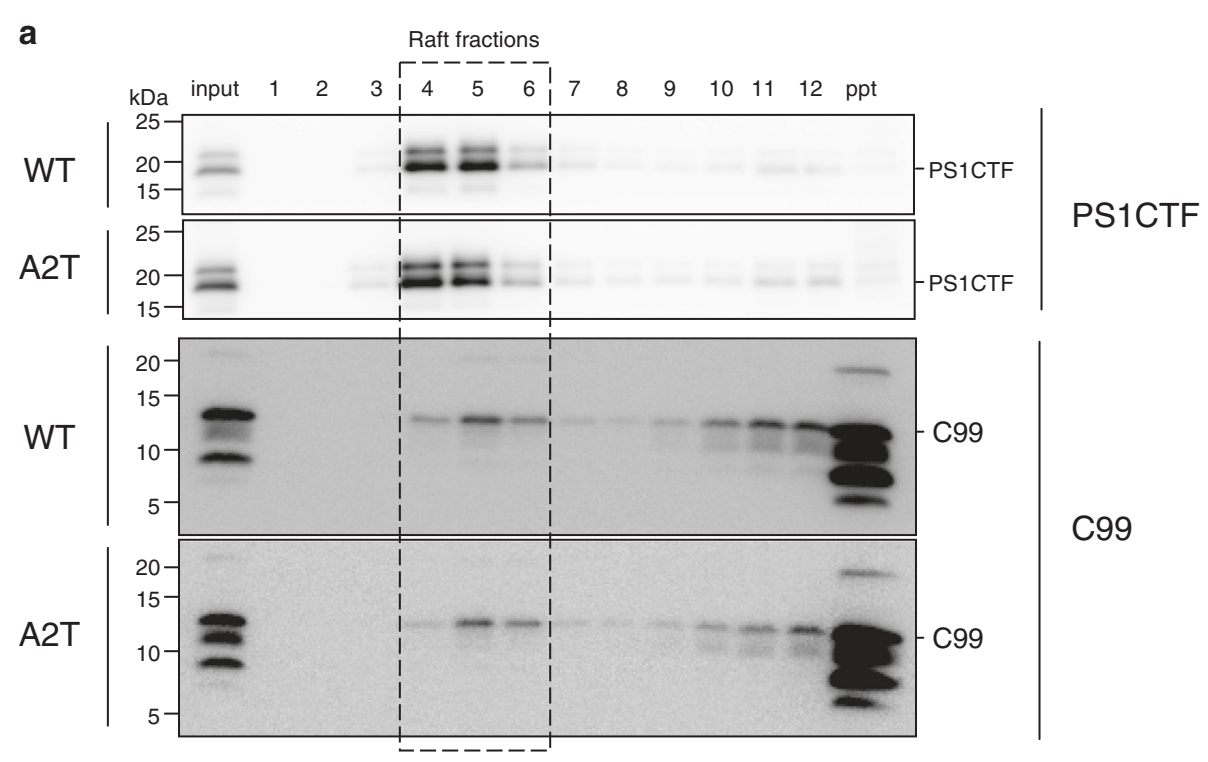

b
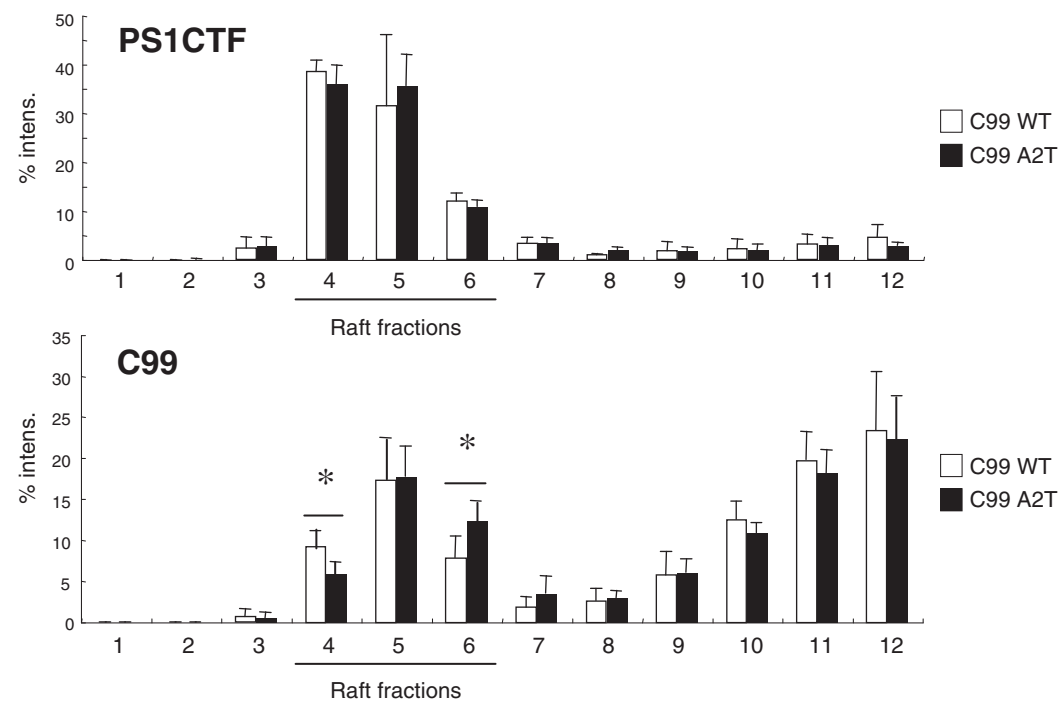

Fig. 7 C99 A2T cells were treated with CHAPSO and fractionated using sucrose gradient centrifugation (a). The presenilin 1 carboxyl terminal fragment (PS1CTF) was enriched in raft fractions (\#4 and \#5). C99 was also distributed in these fractions, in part. However, C99 A2T distribution was significantly shifted into denser fractions (\#5 and \#6) compared with C99 WT (\#4, \#5, and \#6) (b). Data represent means \pm SD of three independent experiments. NS, not significant. ${ }^{*} P<0.05$ (unpaired $t$-test)

assay in a biochemical analysis, we chose a cell-free assay that used the microsomal fraction of cells. This approach provides an assessment of $A \beta$ production in intact membranes. As expected, the cell-free assay reproduced the altered $A \beta$ production in a membrane fraction of $\mathrm{C} 99$ A2T cells. This suggests that the subcellular distribution of $\mathrm{C} 99 \mathrm{~A} 2 \mathrm{~T}$ is altered, and that this redistribution reduces the interaction between C99 A2T and $\gamma$-secretase.

\section{Conclusion}

This report indicates that the C99 level in APP A673T cells is comparable to that in APP WT cells despite a significant reduction in released sAPP $\beta$ level, suggesting vulnerable correlation between levels of sAPP $\beta$ and C99 in cells. Our data demonstrate that the A673T mutation in C99 impairs $\gamma$-cleavage the in cell-based assay. Assessment of observed results in vivo may be crucial to elucidate the protective mechanism of A673T mutation against $\mathrm{AD}$.

\section{Availability of supporting data}

The data set supporting the results of this article are included within the article and its additional files. 


\section{Additional file}

Additional file 1: Figure S1. Immunoreactivity of anti-A $\beta$ antibodies. Recognition sites of anti-A $\beta$ antibodies in the human C99/A $\beta$ sequence (A). A recombinant C99-FLAG containing the A2T substitution was subjected to Western blotting using anti-A $\beta$ antibodies (B). A $\beta 40$ containing the $\mathrm{A} 2 \mathrm{~T}$ substitution was subjected to Western blotting using anti-A $\beta$ antibodies (C). 82 E1 failed to recognize C99-FLAG and A 40 containing the A2T substitution. Figure S2. Immunoprecipitation of C99 A2T in APP A673T cells. CHO cells expressing APP A673T were solubilized in 1\% NP40 and subjected to immunoprecipitation with 6E10 or 82E1 and to Western blotting, to visualize C99 (upper panel) (A). Immunoprecipitation with 6E10 proved that the level of C99 (C99 A2T) in APP A673T cells was indistinctive of that observed in APP WT cells; however, 82E1 failed to capture C99 A2T (upper and lower panels). These data indicate that the amount of C99 in APP A673T cells was comparable to that detected in APP WT cells. Arrowheads, lgG; * degradation products of APP.CHO cells expressing APP A673T were solubilized in 1\% NP40 and subjected to immunoprecipitation with anti-FLAG M2 antibody and to Western blotting (B). Anti-FLAG M2 antibody visualized equal levels of C99 in APP WT and A673T cells (left panel). The blot was reprobed with $82 \mathrm{E} 1$ after stripping anti-FLAG M2 (right panel). 82E1 failed to visualize C99 from APP A673T cells, although remnant bands were detected on the blot. These data indicate that the amount of C99 in APP A673T cells was comparable to that detected in APP WT cells. Arrowheads, IgG. Figure S3. Cells expressing APP A673T and C99 A2T exhibited decreased extracellular A $\beta$ production. HEK293, Neuro 2a, and CHO cells were transfected with the APP A673T or C99 A2T construct. Conditioned media were subjected to Western blotting, to visualize and quantify extracellular $A \beta$, as in Fig. 2A. HEK, HEK293; N2a, Neuro 2a. Data represent means \pm SD of three independent experiments. ${ }^{*} \mathrm{P}<0.05$; ${ }^{* *} \mathrm{P}<0.005$ (unpaired t-test). Figure S4. No effect of the C99 A2T substitution on the subcellular distribution of $\mathrm{Y}^{-}$ secretase components. $\gamma$-Secretase components were enriched in lipid raft fractions, as well as caveolin and flotilin raft markers (\#4 - \#6) (A). The C99 substrate also localized in the fractions, in part; however, C99 A2T was distributed in denser fractions (\#5 and \#6) of raft fractions compared with C99 WT (\#4, \#5, and \#6) (see Fig. 1B and C). mNCT, mature nicastrin. Quantitative analysis of the distribution of g-secretase components and C99 substrates (B). C99 A2T was distributed in denser fractions (\#5 and \#6) compared with C99 WT (\#4, \#5, and \#6) (see Fig. 1B and C). This indicated that the level of C99 A2T that was colocalized with g-secretase was decreased. Data represent means \pm SD of three independent experiments. No significant difference was observed between C99 WT and C99 A2T (unpaired t-test). Individual C99 blots of each experiment (C). Levels of C99 A2T in fraction 4 were lower than those in fraction 6. However levels of C99 WT in fraction 4 were equivalent or higher than those in fraction 6. Figure S5. C99 in membrane, cytosolic and nuclear fractions. C99 cells are homogenized PEPES buffer containing $250 \mathrm{mM}$ sucrose. Postnuclear fraction was subjected to ultracentrifugation at $100,000 \mathrm{~g}$ for $1 \mathrm{~h}$. The pellet was resuspended in the original volume of the PIPES buffer and referred to as membrane fraction. Each fraction was subjected to western blotting to visualize C99 (A). Band intensities of C99, band A and band B in membrane (Mem), cytosolic (Cyto) and nuclear (Nuc) fractions were quantified (B). No prominent difference was observed between C99 WT and C99 A2T. (PDF $935 \mathrm{~kb}$ )

\section{Abbreviations}

AD: Alzheimer's disease; AICD: APP intracellular domain; APP: amyloid precursor protein; A $\beta$ : $\beta$-amyloid protein; C99: $\beta$-carboxyl fragment of APP; FAD: familial AD; IRES: internal ribosome entry site; SAPP $\beta$ : soluble APP fragment processed by $\beta$-secretase; WT: wild-type.

\section{Competing interests}

The authors declare that they have no competing interest.

\section{Authors' contributions}

AK, YI and SF designed experiments. AK, SI, HF, MN, MI and SF performed experiments and analyzed data. SI and SF wrote the manuscript. All authors read and approved the final manuscript.

\section{Acknowledgements}

We wish to thank Dr. A. Asami, Takeda Chemical Industries, for BA27 and BC05; Drs. T. Tomita and T. Iwatsubo, The University of Tokyo, for the anti-PS1-CTF anti-serum; Dr. A. Takashima, National Center for Geriatrics and Gerontology, for anti-Pen-2 antibody and Dr. F. Kametani, Tokyo Institute of Psychiatry, for E50. This work was supported in part by The Takeda Science Foundation (to S.F.), Izumi Science Technology Foundation (to S.F.) and The Naito Foundation (to S.F.).

\section{Author details}

${ }^{1}$ Department of Neuropathology, Graduate School of Life and Medical Sciences, Doshisha University, Kyotanabe, Kyoto 610-0394, Japan.

${ }^{2}$ Department of Neuropathology, Graduate School of Brain Sciences, Doshisha University, Kizugawa, Kyoto 619-0225, Japan.

Received: 16 September 2015 Accepted: 22 October 2015 Published online: 04 November 2015

\section{References}

1. Haass C, Koo EH, Mellon A, Hung AY, Selkoe DJ. Targeting of cell-surface beta-amyloid precursor protein to lysosomes: alternative processing into amyloid-bearing fragments. Nature. 1992;357:500-3.

2. Vassar R, Bennett BD, Babu-Khan S, Kahn S, Mendiaz EA, Denis P, et al. Beta-secretase cleavage of Alzheimer's amyloid precursor protein by the transmembrane aspartic protease BACE. Science. 1999;286:735-41.

3. De Strooper B, Saftig P, Craessaerts K, Vanderstichele H, Guhde G, Annaert W, et al. Deficiency of presenilin-1 inhibits the normal cleavage of amyloid precursor protein. Nature. 1998;391:387-90.

4. Wolfe MS, Xia W, Ostaszewski BL, Diehl TS, Kimberly WT, Selkoe DJ. Two transmembrane aspartates in presenilin-1 required for presenilin endoproteolysis and gamma-secretase activity. Nature. 1999;398:513-7.

5. Selkoe DJ. Alzheimer's disease: genes, proteins, and therapy. Physiol Rev. 2001;81:741-66.

6. Iwatsubo T, Odaka A, Suzuki N, Mizusawa H, Nukina N, Ihara Y. Visualization of A beta 42(43) and A beta 40 in senile plaques with end-specific Abeta monoclonals: evidence that an initially deposited species is A beta 42(43). Neuron. 1994;13:45-53.

7. Sato T, Dohmae N, Qi Y, Kakuda N, Misonou H, Mitsumori R, et al. Potential link between amyloid beta-protein 42 and C-terminal fragment gamma 49-99 of beta-amyloid precursor protein. J Biol Chem. 2003;278:24294-301.

8. Funamoto S, Morishima-Kawashima M, Tanimura Y, Hirotani N, Saido TC, Ihara Y. Truncated carboxyl-terminal fragments of beta-amyloid precursor protein are processed to amyloid beta-proteins 40 and 42. Biochemistry. 2004;43:13532-40.

9. Jonsson T, Atwal JK, Steinberg S, Snaedal J, Jonsson PV, Bjornsson S, et al. A mutation in APP protects against Alzheimer's disease and age-related cognitive decline. Nature. 2012;488:96-9.

10. Hardy J, Selkoe DJ. The amyloid hypothesis of Alzheimer's disease: progress and problems on the road to therapeutics. Science. 2002;297:353-6.

11. Hardy JA, Higgins GA. Alzheimer's disease: the amyloid cascade hypothesis. Science. 1992;256:184-5.

12. Wang LS, Naj AC, Graham RR, Crane PK, Kunkle BW, Cruchaga C, et al. Rarity of the Alzheimer disease-protective APP A673T variant in the United States. JAMA Neurol. 2015;72:209-16.

13. Ting SK, Chong MS, Kandiah N, Hameed S, Tan L, Au WL, et al. Absence of A673T amyloid-beta precursor protein variant in Alzheimer's disease and other neurological diseases. Neurobiol Aging. 2013;34:e2447-8.

14. Mengel-From, J, Jeune B, Pentti T, McGue M, Christensen K, Christiansen L. The APP A673T frequency differs between Nordic countries. Neurobiol Aging. 2015;36: 2909 e1-4.

15. Liu YW, He YH, Zhang YX, Cai WW, Yang LQ, Xu LY, et al. Absence of A673T variant in APP gene indicates an alternative protective mechanism contributing to longevity in Chinese individuals. Neurobiol Aging. 2014;35:935. e911-932.

16. Kero M, Paetau A, Polvikoski T, Tanskanen M, Sulkava R, Jansson L, et al. Amyloid precursor protein (APP) A673T mutation in the elderly Finnish population. Neurobiol Aging. 2013;34:1518. e1511-1513.

17. Bamne MN, Demirci FY, Berman S, Snitz BE, Rosenthal SL, Wang X, et al. Investigation of an amyloid precursor protein protective mutation (A673T) in a North American case-control sample of late-onset Alzheimer's disease. Neurobiol Aging. 2014;35:1779. e1715-1776.

18. Maloney JA, Bainbridge T, Gustafson A, Zhang S, Kyauk R, Steiner P, et al. Molecular mechanisms of Alzheimer disease protection by the A673T allele of amyloid precursor protein. J Biol Chem. 2014;289:30990-1000. 
19. Benilova I, Gallardo R, Ungureanu AA, Castillo Cano V, Snellinx A, Ramakers $M$, et al. The Alzheimer disease protective mutation A2T modulates kinetic and thermodynamic properties of amyloid-beta (Abeta) aggregation. J Biol Chem. 2014;289:30977-89.

20. Shah S, Lee SF, Tabuchi K, Hao YH, Yu C, LaPlant Q, et al. Nicastrin functions as a gamma-secretase-substrate receptor. Cell. 2005;122:435-47.

21. Funamoto $S$, Sasaki T, Ishihara S, Nobuhara M, Nakano M, WatanabeTakahashi $\mathrm{M}$, et al. Substrate ectodomain is critical for substrate preference and inhibition of gamma-secretase. Nat Commn. 2013;4:2529.

22. Horikoshi Y, Sakaguchi G, Becker AG, Gray AJ, Duff K, Aisen PS, et al. Development of $A B$ terminal end-specific antibodies and sensitive ELISA for Aß variant. Biochem Biophys Res Commun. 2004;319:733-7.

23. Kume H, Kametani F. Abeta 11-40/42 production without gamma-secretase epsilon-site cleavage. Biochem Biophys Res Commun. 2006;349:1356-60.

24. Lichtenthaler SF, Multhaup G, Masters CL, Beyreuther K. A novel substrate for analyzing Alzheimer's disease gamma-secretase. FEBS Lett. 1999;453:288-92.

25. Qi-Takahara Y, Morishima-Kawashima M, Tanimura Y, Dolios G, Hirotani N, Horikoshi $Y$, et al. Longer forms of amyloid beta protein: implications for the mechanism of intramembrane cleavage by gamma-secretase. J Neurosci. 2005;25:436-45

26. Kakuda N, Funamoto S, Yagishita S, Takami M, Osawa S, Dohmae N, et al. Equimolar production of amyloid beta-protein and amyloid precursor protein intracellular domain from beta-carboxyl-terminal fragment by gamma-secretase. J Biol Chem. 2006:281:14776-86.

27. Gu Y, Misonou H, Sato T, Dohmae N, Takio K, Ihara Y. Distinct intramembrane cleavage of the beta-amyloid precursor protein family resembling gamma-secretase-like cleavage of Notch. J Biol Chem. 2001:276:35235-8

28. Wada S, Morishima-Kawashima M, Qi Y, Misono H, Shimada Y, OhnoIwashita $Y$, et al. Gamma-secretase activity is present in rafts but is not cholesterol-dependent. Biochemistry. 2003;42:13977-86.

29. Osawa S, Funamoto S, Nobuhara M, Wada-Kakuda S, Shimojo M, Yagishita S, et al. Phosphoinositides suppress gamma-secretase in both the detergentsoluble and -insoluble states. J Biol Chem. 2008;283:19283-92.

30. Vetrivel KS, Cheng H, Lin W, Sakurai T, Li T, Nukina N, et al. Association of gsecretase with lipid rafts in post-Golgi and endosome membranes. J Biol Chem. 2004:279(43):44945-54

31. Vetrivel KS, Cheng H, Kim SH, Chen Y, Barnes NY, Parent AT, et al. Association of gamma-secretase with lipid rafts in post-Golgi and endosome membranes. J Biol Chem. 2005;280:25892-900.

32. Hur JY, Welander H, Behbahani H, Aoki M, Franberg J, Winblad B, et al. Active gamma-secretase is localized to detergent-resistant membranes in human brain. FEBS J. 2008;275:1174-87.

33. Fukumoto $\mathrm{H}$, Takahashi $\mathrm{H}$, Tarui $\mathrm{N}$, Matsui J, Tomita T, Hirode M, et al. A noncompetitive BACE1 inhibitor TAK-070 ameliorates Abeta pathology and behavioral deficits in a mouse model of Alzheimer's disease. J Neurosci. 2010;30:11157-66.

34. Willem M, Tahirovic S, Busche MA, Ovsepian SV, Chafai M, Kootar S, et al. etaSecretase processing of APP inhibits neuronal activity in the hippocampus. Nature. 2015:526:443-7.

\section{Submit your next manuscript to BioMed Central and take full advantage of:}

- Convenient online submission

- Thorough peer review

- No space constraints or color figure charges

- Immediate publication on acceptance

- Inclusion in PubMed, CAS, Scopus and Google Scholar

- Research which is freely available for redistribution

Submit your manuscript at www.biomedcentral.com/submit 